\title{
Flow and Ductility of Smectite Clay for Skin Treatment
}

\author{
Roland Pusch \\ Luleå University of Technology, Lund, Sweden \\ Email: drawrite.se@gmail.com
}

Received 31 October 2013; revised 30 November 2013; accepted 8 December 2013

Copyright (c) 2014 by author and Scientific Research Publishing Inc.

This work is licensed under the Creative Commons Attribution International License (CC BY). http://creativecommons.org/licenses/by/4.0/

(c) (i) Open Access

\begin{abstract}
It is important that pastes and creames for skin treatment have suitable rheological properties and ability to establish a good contact with the tissues while retaining their tightness. Thixotropy is desired for providing fluidity when agitated and a suitably degree of stiffening thereafter. This requires low shear resistance in the coating phase and microstructural reorganization when leaving the paste to rest. Following the principle of using only mineral components for skin treatment, use of expandable hydrophilic clay minerals should be considered. They sorb cations and positively charged organic molecules and are impermeable to fluids and gas under low pressure, hence providing oxygen-free micro-environment. They can balance $\mathrm{pH}$ and are excellent agents for cleaning skin.
\end{abstract}

Keywords

Smectite Clay; Skin Treatment

\section{Introduction}

Greasy organic bases may interfere with the skin function at heat radiation and sweat excretion and be irritant to the skin. In contrast, pure mineral-based creams and pastes have shown promising properties for serving as sunradiation protective agents and some other functions but they are less good in other respects, particularly by comprehensive microfissuring on desiccation. Smectite in the form of montmorillonite in combination with other silicious clay components like talc and palygorskite serves better. Talc has the ability to adhere readily to skin and to block pores. Palygorskite, a mineral used in the chemical industry [1] [2], can serve as stabilizer for minimizing shrinkage.

Smectite in the form of montmorillonite will be the focus of this paper for its tightness, sorbing capacity and gas-isolating properties, which are due to the constitution of the mineral crystallites shown in Figure 1. The lay- 


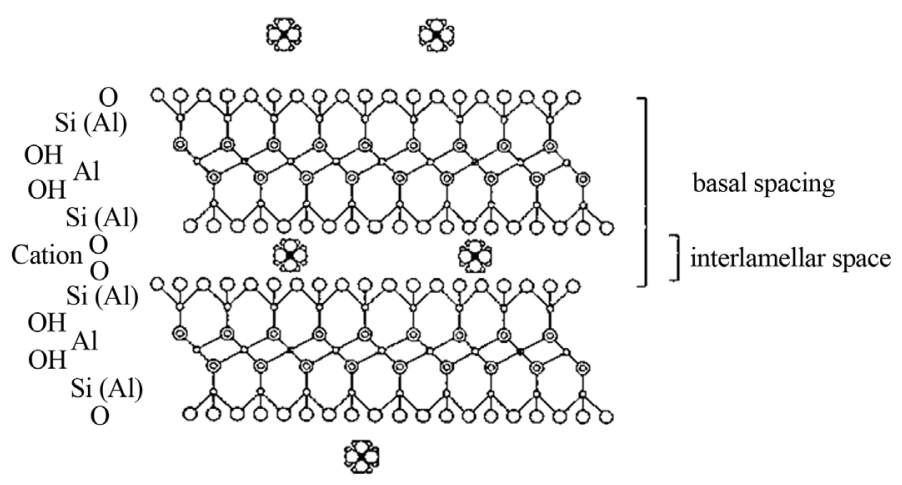

Figure 1. Crystal constitution of a stack of two montmorillonite lamellae with $1 \mathrm{~nm}$ thickness. Cations and water molecules, which can form up to 3 hydrates are located in the interlamellar space [3].

ers, consisting of $1 \mathrm{~nm}$ thick parallel lamellae of Si-O/Al-OH atoms, carry electrical charges that are balanced by cations sorbed in the interlamellar space, which also hosts water, and on the outer surfaces.

\section{Physical Properties of Smectite Clay in a Modern Perspective}

\subsection{Microstructural Constitution}

The stress/strain behaviour of smectite clay has been investigated in detail in soil physics and applied geological engineering since dense material of this type serves as a very effective isolating medium of radioactive matter due to its low hydraulic conductivity and high cation exchange capacity. The experience is directly applicable to the cosmetic branch as indicated in this paper. The basis of the description of the performance of smectite clay is the concept of physical interaction between neighbouring particles as illustrated by Figure 2. It indicates that exchange of sorbed cations can cause substantial change in bulk expandability and thereby in coherence and tightness.

Inorganic pastes and creams perform according to the physical interaction of the particles. This means that exchange of initially sorbed cations and positively charged molecules can change the attractive and repulsive forces between them and that this can change the physical properties in bulk. The role of chlorides in sweat is of particular importance. It does not cause any exchange of original sodium in the exchange positions of the smectite crystal lattices but leads to strong coagulation and growth of pores in the soft microstructural network (Figure 3). Thixotropy has the same effect, meaning that a coating of smectite clay changes from being very soft to become stiff in less than a minute [3].

On exposing water-saturated montmorillonite to air with RH lower than about $80 \%$ desiccation leads to intense fissuring and loss of tightness with respect to fluids and gas compared to the state at complete fluid saturation. Like for cementitious materials chemically compatible agents can, however, provide microstructural reinforcement and stability and for montmorillonite and its smectite relatives, saponite (Mg-rich), nontronite (Ferich), beidellite (Al-rich) etc, lath-shaped minerals like halloysite (a kaolinite-like species) or palygorskite (attapulgite) can be considered (Figure 4) [2]. Such components can minimize shrinkage and provide coherence and tightness of the paste (Figure 5).

Figure 5 illustrates that the typical polygon-like fine-fissuring of dried montmorilloniteclay has a number of fissures of about 2 per square centimeter, while the number is 0.2 per square centimeter for the clay consisting of equal amounts of montmorillonite and palygorskite. The aperture of the cracks is about the same in both samples meaning that the palygorskite-mixed montmorillonite retained its homogeneity and tightness much better than the sample of pure montmorillonite. Even more important fact is that drying in air of initially water-saturated clay of the latter type at $\mathrm{RH} 70 \%-80 \%$ and $37^{\circ} \mathrm{C}$ does not cause desiccation-induced fissures in the last-mentioned clay.

\subsection{Density Andconsistency of Smectites for Skin Treatment}

\subsubsection{Creames and Pastes of Smectite Clay}

The dry bulk density (ratio of the solid mass of clay dried at $105^{\circ} \mathrm{C}$ and the volume including voids) of clay for 


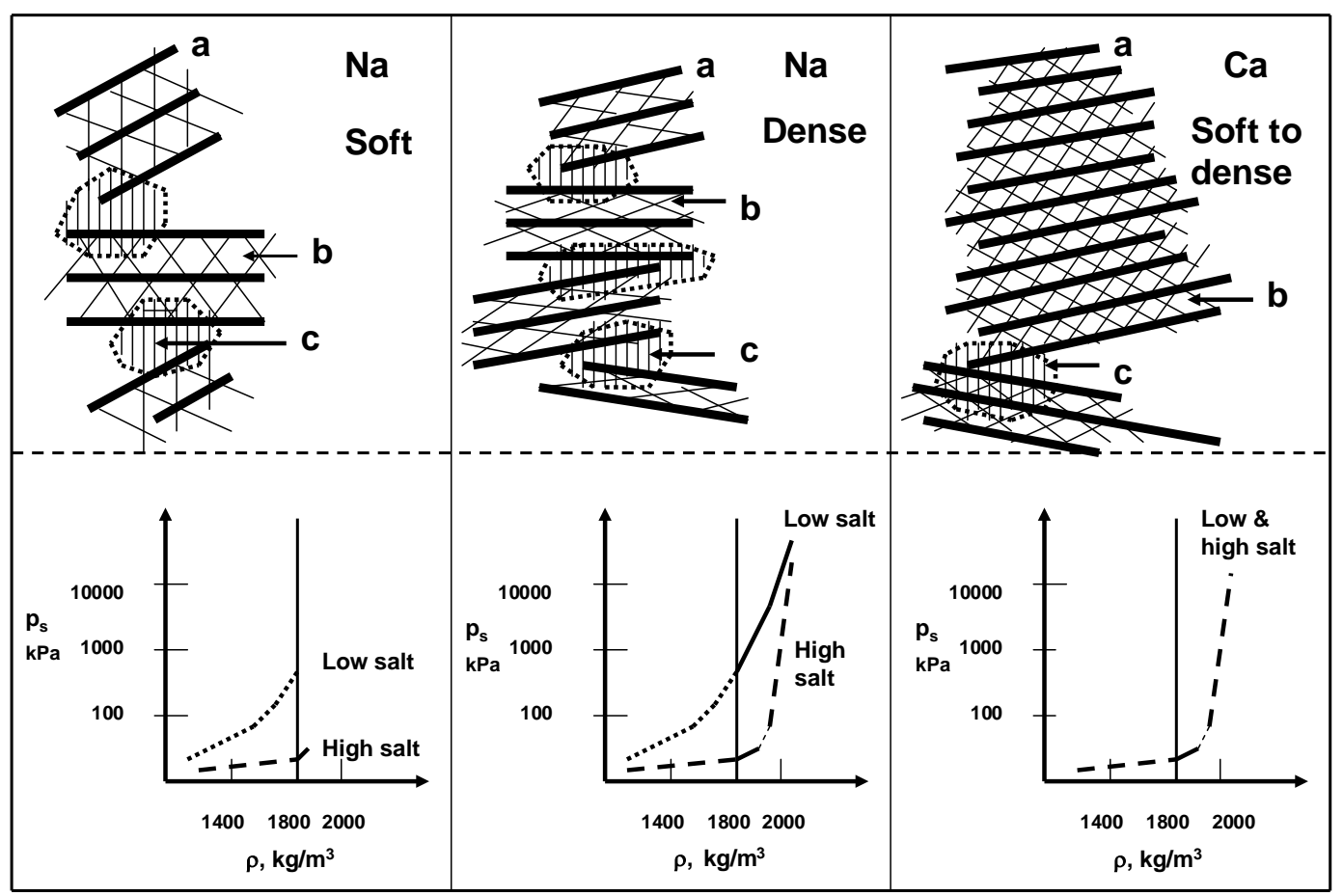

Figure 2. Schematic pictures of stacks of lamellae and influence of density and pore water salinity on the particle spacing and swelling pressure $\left(\mathrm{p}_{\mathrm{s}}\right)$. (a) Lamella; (b) Interlamellar space; (c) Contact region with interacting electrical double-layers, exposed hydroxyls and polarized sorbedcations [3].
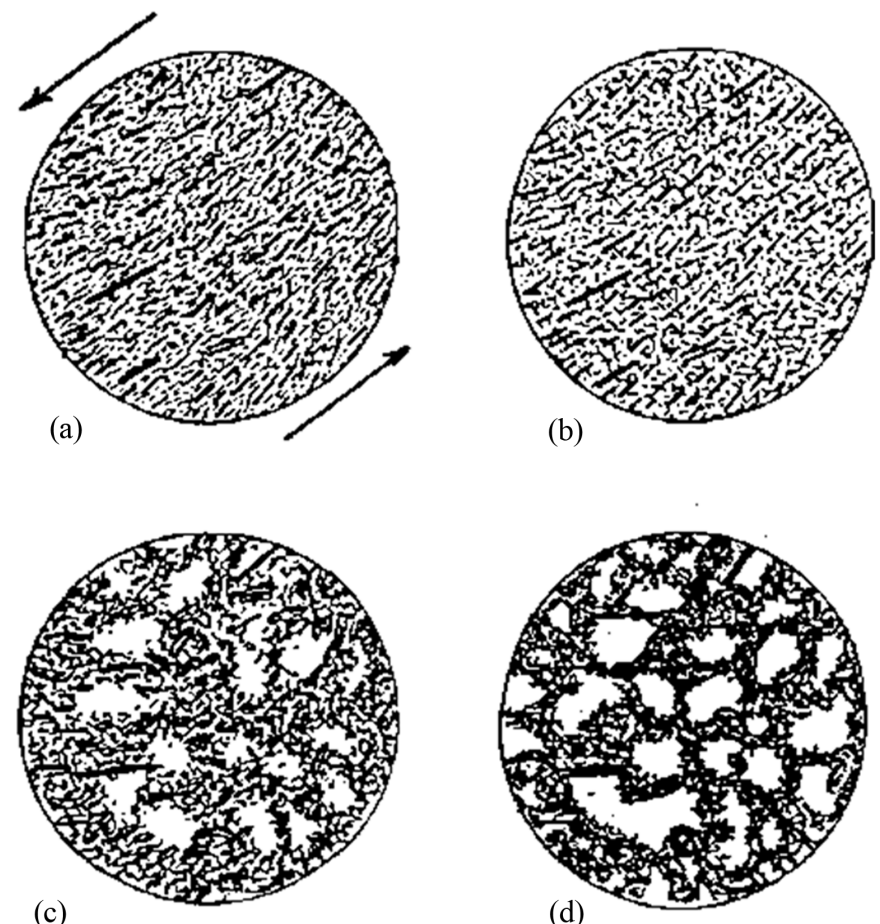

$$
0.5 x
$$

Figure 3. Microstructural stages in stiffening smectite paste. (a) Freshly placed; (b) Early coagulation by edge-to base attraction of adjacent particles; (c) Early coagulation stage; (d) Ultimate coagulation. 


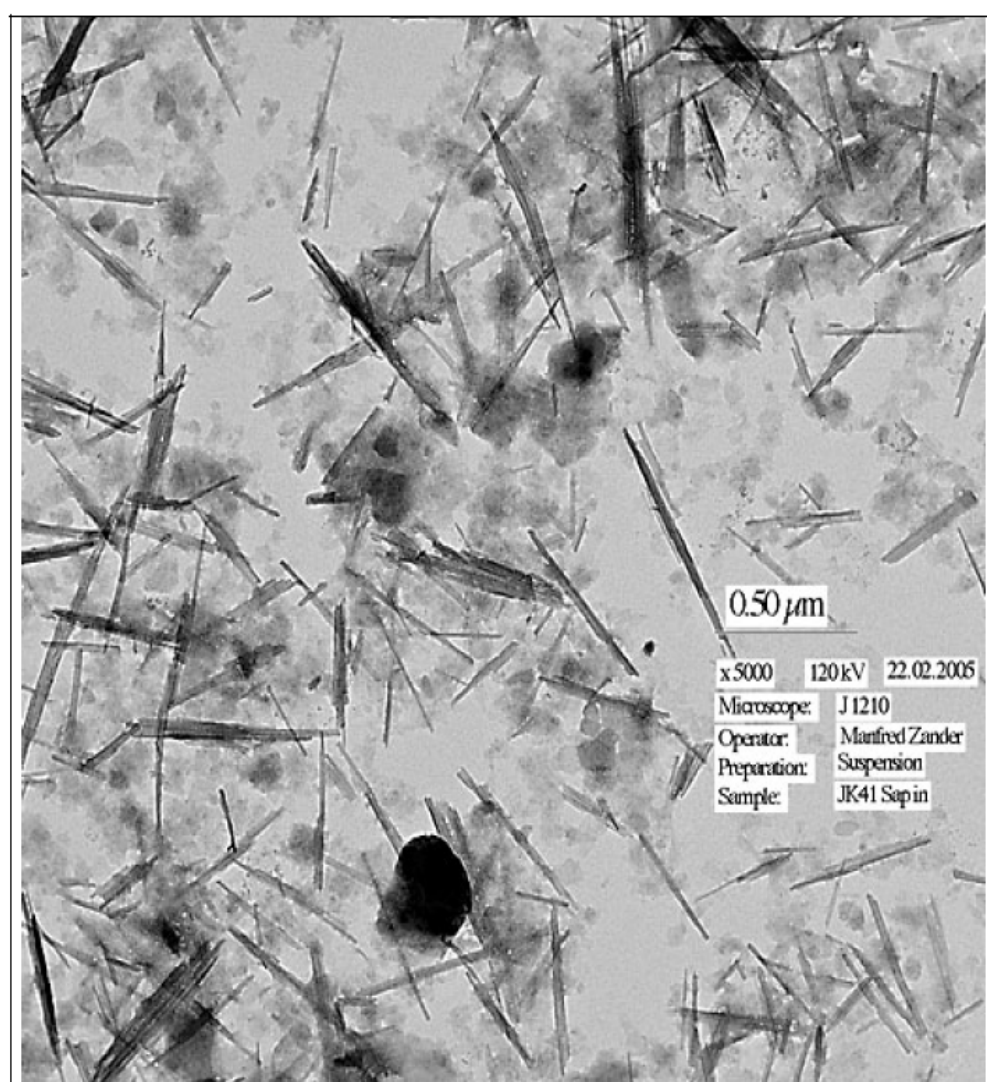

Figure 4. Mixture of smectite and palygorskite, mass ratio 1:1. The laths are palygorskite with similar crystal lattices as montmorillonite but with different shape (Photo by Manfred Zander Greifswald University, Germany).
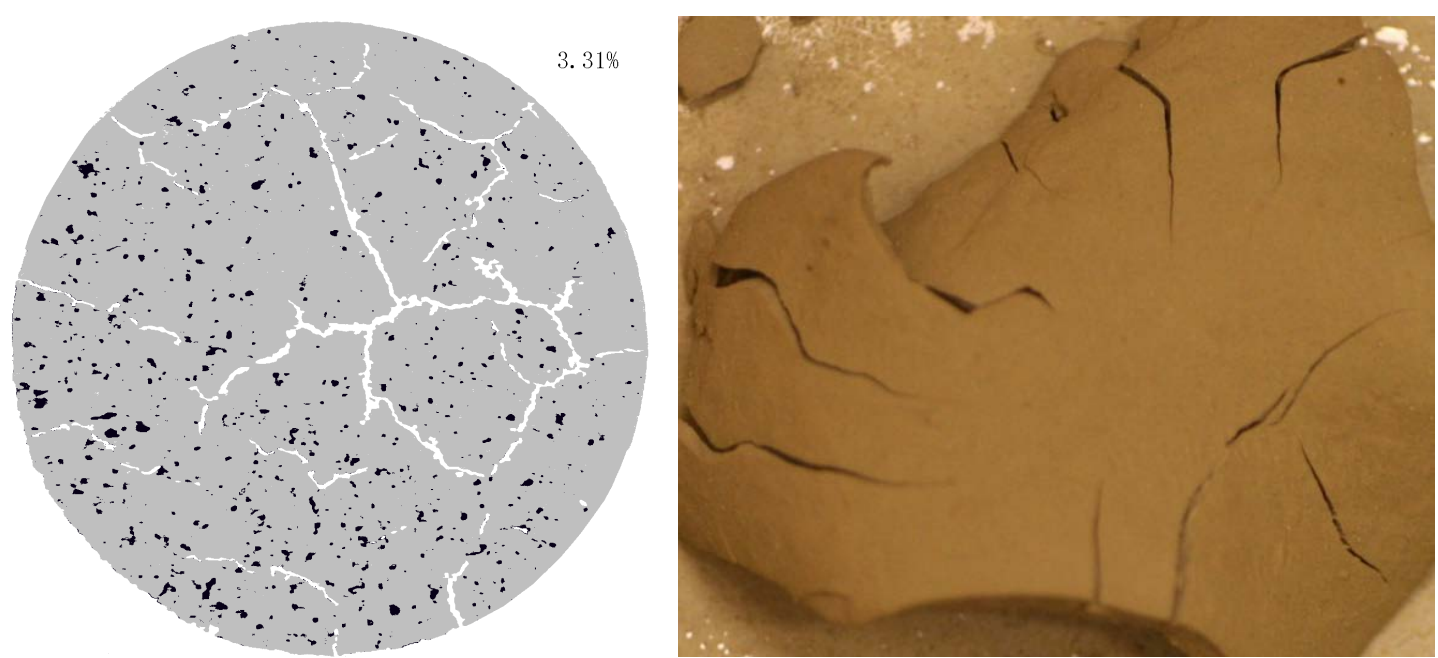

Figure 5. Fissuring in pure medium-dense montmorillonite-rich clay (left) and in a mixture of $50 \%$ palygorskite and montmorillonite clay (right) after drying at $105^{\circ} \mathrm{C}$. The diameter of the circular specimen is $30 \mathrm{~mm}$; the scale is the same for both. The blue spots in the left micrograph are Methylene Blue used for identifying permeable flow paths before drying (Photo by M.Hatem Mohammed).

use in dermatology ranges between about $160 \mathrm{~kg} / \mathrm{m}^{3}$ and $790 \mathrm{~kg} / \mathrm{m}^{3}$. The void ratio (ratio of pore volume and total volume) is about 16.5 and the water content (ratio of mass of water and solid mass of clay) about $590 \%$ for the lower density and 2.5 and $89 \%$, respectively, for the higher. A most useful measure of the consistency of 
water-saturated clay is the Atterberg liquid limit $\left(\mathrm{w}_{\mathrm{L}}\right)$ [3], which is the water content that makes the clay semi-fluid, and which is about $300 \%$ for smectites saturated with sodium and about $100 \%$ for saturation with calcium or magnesium. This limit is a measure of the water-sorbing potential of a clay.

For easy placement on skin the density of pure smectite clay pastes saturated with distilled water can be in the interval $1050 \mathrm{~kg} / \mathrm{m}^{3}$ (dry density $80 \mathrm{~kg} / \mathrm{m}^{3}$ ) to $1300 \mathrm{~kg} / \mathrm{m}^{3}$ (dry density $480 \mathrm{~kg} / \mathrm{m}^{3}$ ). Ongoing R \& D shows that the amount of the thixotropic stabilizer palygorskite required for providing cohesion and absence of fractures and voids ranges between $25 \%$ and $75 \%$ depending on the humidity of the environment and the skin.

\subsubsection{Tightness of Smectite Clay}

Water-saturated smectite clay membranes let fluids and gas through only by diffusion if the pressure difference is low. By increasing the pressure on one side there is a threshold value at which "piping" occurs and fluid and gas make their way through the cream or paste [3]. This critical pressure depends on the hydraulic gradient, i.e. the drop in pressure across the clay membrane divided by the thickness of the clay. It is commonly 10 to 30 $\left.\left[\left(\mathrm{N} / \mathrm{m}^{2}\right) / \mathrm{m}\right)\right]$, [4]. The penetration is peristaltic because the self-sealing potential of the clay is very high and provides temporary tightness after each penetration. For water and gas pressures that are low enough to avoid piping the average hydraulic conductivity of smectite clay with a density at water saturation of $1100 \mathrm{~kg} / \mathrm{m}^{3}$ is on the order of E-6 m/s while it can be 1000 times higher for gas. This difference is explained by the much higher viscosity of water and the capillary retention caused by the extreme fineness of the pores even in soft smectite clay (Figure 6).

\subsection{Interaction of Smectite and Epidermis}

\subsubsection{Coupling Mechanisms}

One realizes from the aforementioned that even very soft smectite pastes and creames give excellent isolation of skin that they are smeared on because of their hydrophilic nature. The interaction of smectite clay particle surfaces and skin is both by direct bonding through the action of hydrogen bonds and direct coupling via carboxyl groups or bond-sharing of adsorbed cations and positively charged molecules. The combined action of these mechanisms makes the attraction of smectite clay gels or pastes to skin strong. Once placed, the major time-related processes in the smeared-on smectite clay are uptake of cations and positively charged organic molecules from the skin and migration of fluids from or into it depending on the nature of the fluid and the relative degree of wetting. These processes take place by diffusion in epidermis and by flow and diffusion in more shallow skin. A properly composed smectite clay paste sorbs organic matter from the latter and hence has a cleaning effect. Repeated coating of skin with smectite gel, that is easily washed off, will help to clean and freshen the skin.

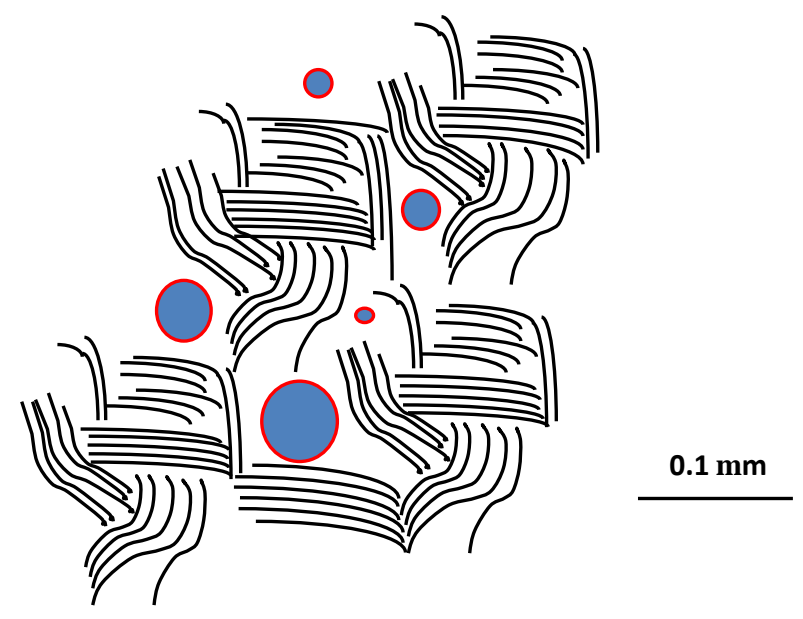

Figure 6. Schematic microstructural constitution of water-saturated smectite clay. The lines represent stacks of parallel smectite lamellae, which have a thickness of down to $1 \mathrm{~nm}$. The space between them is occupied by highly viscous water with cations or positively charges molecules. 


\subsubsection{Performance of Smectite Creames on Skin}

The most important functions of smectite creames and pastes are, in summary:

*Cleaning effect. The huge specific surface area of smectite, about $1000 \mathrm{~m}^{2}$ per gram solid clay, provides a very large number of hydrogen bonds between organic debris and clay. Washing after treatment effectively cleans the skin,

*Gas tightness. A number of processes in epidermis generate gas. Coating by tight clay has a retarding effect on these processes and can affect healing by creating oxygen-free conditions. This may, for example, retard and cure acne. A condition for gas tightness is that the pasted clay does not totally desiccate and become fissured. This can be hindered by mixing montmorillonitic clay with palygorskite that serves as reinforcement and preserves microstructural cohesion,

${ }^{*} \mathrm{pH}$ effects. Smectite gels have high $\mathrm{pH}(9$ - 10) but adding chlorides can bring it down by several units by dissolving clay crystals causing loss of protons and uptake of available cations. This process takes place when there is sweat on the skin, which hence means that treatment of such skin with smectite gel or paste can both pick up organic debris and cause chemical neutrality. Air-dry powdered smectite mixed with palygorskite has a drying effect and transforms it from a powdered state to gel forms with time.

\section{Conclusion}

Smectite clay has a number of properties that can be used in dermatology and cosmetics. The most important ones are the cleaning effect by repeated treatment, the capacity to remove or bring in soluble cations and organic molecules in shallow and deep parts of the skin, and to provide an air-tight coating of wounds. The latter can be especially effective in treatment of acne by the potential to sorb positively charged bacteria and virus from the skin and to provide protection against invasion of such species.

\section{References}

[1] Jones, B.F. and Galan, E. (1988) Sepiolite and Palygorskite. Reviews in Mineralogy and Geochemistry, 19, 631-674.

[2] Arnold, D.E. (2005) Maya Blue and Palygorskite: A Second Possible Pre-Columbian Source. Ancient Mesoamerica, 16, 51-62. http://dx.doi.org/10.1017/S0956536105050078

[3] Pusch, R. and Yong, R.N. (2006) Microstructure of Smectite Clays and Engineering Performance. Taylor \& Francis, London and New York.

[4] Pusch, R. (2008) Geological Storage of Radioactive Waste. Springer Verlag, Berlin and Heidelberg. http://dx.doi.org/10.1007/978-3-540-77333-7 